\title{
Obesity and bullying: different effects for boys and girls
}

\author{
L J Griffiths, D Wolke, A S Page, J P Horwood, the ALSPAC Study Team

See end of article for authors' affiliations

.....................

Correspondence to: Dr L J Griffiths, Centre for Paediatric Epidemiology and Biostatistics, Institute of Child Health, 30 Guilford Street, London WCIN 1EH, UK; I.griffiths@ ich.ucl.ac.uk

Accepted 3 August 2005 Published Online First 20 September 2005
Aims: To investigate whether weight category (underweight, average weight, overweight, and obese) at age 7.5 predicts bullying involvement at 8.5 years. Models were tested separately for boys and girls to investigate gender differences in association patterns.

Methods: Prospective cohort study in southwest England. Height and weight were measured in children at age $7.5(\mathrm{n}=8210)$. BMI $\left(\mathrm{kg} / \mathrm{m}^{2}\right)$ was used to define underweight, average weight, overweight, and obese children, according to British age and gender specific growth reference data. Overt $(n=7083)$ and relational $(n=6932)$ bullying behaviour was assessed in children at age 8.5.

Results: After adjustment for parental social class, compared to average weight boys, obese boys were 1.66 (95\% Cl 1.04 to 2.66 ) times more likely to be overt bullies and 1.54 (1.12 to 2.13 ) times more likely to be overt victims. Obese girls were 1.53 (1.09 to 2.15$)$ times more likely to be overt victims compared to average weight girls.

Conclusions: Obesity is predictive of bullying involvement for both boys and girls. Preadolescent obese boys and girls are more likely to be victims of bullying because they deviate from appearance ideals. Other obese boys are likely to be bullies, presumably because of their physical dominance in the peer group.
$\mathrm{T}$ he prevalence of childhood obesity is rapidly increasing and has doubled in the last two decades. ${ }^{12}$ Obesity in children is associated with undesirable psychological and social consequences, including impaired peer relationships, school experiences, and poor psychological wellbeing..$^{3-5}$ Peers more often report negative attitudes towards obese children, ${ }^{6}$ while overweight and obese adolescents have been reported to be more often victimised than their average weight peers. ${ }^{7-10}$

Bullying victimisation refers to a student being repeatedly exposed to negative actions of other students with the intention to hurt, ${ }^{11}$ and it usually involves an imbalance in strength, either real or perceived. ${ }^{12}$ It can be overt (physical (e.g. hitting) or verbal (e.g. name calling)) or relational (e.g. social exclusion), ${ }^{13}$ and is moderately stable by early childhood. ${ }^{15}$ Bullying victimisation is frequent in school settings across different countries ${ }^{16}$ and, like obesity, has been found to be associated with psychosocial maladjustment including increased anxiety, depressive feelings, loneliness, lowered self-esteem, and behaviour problems. ${ }^{17} 18$

Boys more often experience overt bullying victimisation than girls. ${ }^{15}$ Gender differences are also reported in relational victimisation before adolescence in the USA ${ }^{14}$ but not in European studies. ${ }^{13}{ }^{18}$ Boys are more often victims of physical bullying if they are physically weaker, ${ }^{19} 20$ while recent evidence also suggests that overweight and obese adolescent boys are more likely to be perpetrators of bullying than their average weight peers. ${ }^{8}$ For girls, appearance and the lack of close friendships may expose them more to victimisation. ${ }^{13} 20$ Unknown is whether obesity predisposes preadolescent children to become more often victimised and, in particular, whether the impact of obesity or overweight may be different for boys and girls of this age.

The present study investigated whether weight category (underweight, average weight, overweight, and obese) at age 7.5 predicted bullying involvement a year later, at 8.5 years. Given the evidence of gender differences of bullying behaviour and experiences, separate pathways were examined for boys and girls. We hypothesised that obesity would be predictive of victim status; however, no priori assumptions were made on how weight category would affect bullyperpetrator status.

The association of social class and obesity ${ }^{21}$ suggested that parental (maternal and paternal) social class should be taken into account.

\section{METHODS}

\section{Sample}

We examined data from children of the Avon Longitudinal Study of Parents and Childhood (ALSPAC) ${ }^{22}$ (Www.alspac. bris.ac.uk). The cohort consists of children born to residents of the former Avon Health Authority area who had an expected date of delivery between 1 April 1991 and 31 December 1992. Avon includes urban and rural areas and the population is broadly representative of children in the UK. ${ }^{22}$ Children from the age of 7.5 onwards are attending annual clinics where they are interviewed and tested. This study examined data obtained from children at age 7.5 and 8.5 years, to explore if weight category is an antecedent to bullying status.

\section{Procedures}

Trained researchers measured height and weight at age 7.5 (4163 boys and 4047 girls). Overt ( 3522 boys and 3561 girls) and relational ( 3437 boys and 3495 girls) bullying behaviour was assessed with a standard interview ${ }^{16}$ by trained psychologists at age 8.5. Parental social class (paternal, 3727 boys and 3683 girls; maternal, 3522 boys and 3418 girls) was assessed at birth.

\section{Measures \\ Weight category}

Height was measured to the nearest $0.1 \mathrm{~cm}$ using the Leicester height meter. Body weight was measured to the nearest $0.1 \mathrm{~kg}$ using Seca model 835 scales. Body mass index (BMI), calculated using the formula weight $(\mathrm{kg}) /$ height $(\mathrm{m})^{2}$, was used as a proxy for body fatness. BMI 
Table 1 Forms of overt and relational bullying

\begin{tabular}{ll}
\hline Type & Description \\
\hline Overt bullying & $\begin{array}{l}\text { Having belongings stolen; having been threatened or blackmailed; having been hit or beaten up; having been called bad/nasty names; } \\
\text { having nasty tricks played on them } \\
\text { Other children: not wanting to play with them; trying to get them to do something they didn't want to do; withdrawing friendship; telling } \\
\text { tales on them; spreading lies or nasty rumours; deliberately spoiling games; doing other things to upset them }\end{array}$ \\
\hline Relational bullying
\end{tabular}

was interpreted in relation to British age and gender specific growth reference data, ${ }^{23}$ by means of software obtained from the Child Growth Foundation. ${ }^{24}$ Children were defined as underweight (BMI $<15$ th centile), average weight (BMI 1584.99th centile), overweight (BMI 85-94.99th centile), or obese (BMI $\geqslant 95$ th centile).

\section{Bullying}

Bullying was assessed using a structured face-to-face interview, the Bullying and Friendship Interview Schedule. ${ }^{18}$ Researchers explained to children that they were interested in things that happen in school, or on the way to or from school, in the last six months. Children were asked if they had experienced any forms of received overt or relational bullying (table 1), or if they had used any forms of overt or relational bullying to upset other children.

If children had received forms of bullying, or been perpetrators themselves, they were asked how frequently it had occurred. At no time during the interview was the word bullying used, only behavioural descriptions, so as not to prompt the child.

Three roles of involvement in bullying were distinguished:12 ${ }^{18}$ overt bullies (children who were involved in overtly bullying others frequently or every week); overt victims (children who experienced any of the forms of overt bullying frequently or every week); or overt neutrals (children who neither physically bullied others or became physical victims). The same format was used to classify roles in relational bullying, yielding an overt bullying status (bully, victim, neutral), and relational bullying status (bully, victim, neutral).

\section{Parental social class}

Parental social class (maternal and paternal) was assessed using the Standard Occupational Classification. ${ }^{25}$ Classifications were categorised as manual versus nonmanual occupations.

\section{Statistical analysis}

Multiple logistic regression analysis was used to build two models to predict: (1) overt bullying status (at 8.5 years) based on weight category (underweight, average weight, overweight, and obese) at age 7.5; and (2) relational bullying status (at 8.5 years) based on weight category at age 7.5. Models were built separately for boys and girls. Unadjusted and adjusted analyses were performed with maternal and paternal social class as covariates. Odds ratios were generated and for both models the reference category was average weight. All statistical analyses were conducted with SPSS version 11.0

Ethical approval for the study was obtained from ALSPAC's own Ethics Advisory Committee and the three Avon Medical Ethics Committees.

\section{RESULTS}

\section{Weight categories}

The mean BMI was 16.40 (SD 2.24) $\mathrm{kg} / \mathrm{m}^{2}$ for the girls, and 16.13 (SD 1.95) kg/m² for the boys. Table 2 shows the prevalence of boys and girls within each of the four weight categories.

\section{Prevalence of bullying}

Of the 7083 children (3522 boys and 3561 girls) who completed the overt bullying interview: 497 (7.0\%) were categorised as overt bullies (boys: 365 (10\%); girls: 132 $(4 \%))$; $2000(28 \%)$ as overt victims (boys: 1059 (30\%); girls: $941(26 \%))$; and $4586(65 \%)$ as overt neutrals (boys: 2098 (60\%); girls: $2488(70 \%)$ ). A total of 6932 children (3437 boys and 3495 girls) completed the relational bullying interview, of which $165(2 \%)$ were categorised as relational bullies (boys: 95 (3\%); girls: $70(2 \%)), 1020(15 \%)$ as relational victims (boys: 457 (13\%); girls $563(16 \%)$ ); and 5746 (83\%) as relational neutrals (boys: 2885 (84\%); girls $2861(82 \%)$ ).

Table 3 shows the prevalence of bullying involvement by weight category: $36 \%$ of obese boys were victims of overt bullying, 18\% victims of relational bullying, and 14\% overt bully-perpetrators a year later; while $34 \%$ of obese girls were overt victims, and $17 \%$ relational victims.

\section{Weight predicted bullying status}

Weight category at age 7.5 was found to predict overt bullying status (at age 8.5) for boys $\left(\chi^{2}(6)=22.94\right.$, $\mathrm{p}<0.05)$ and girls $\left(\chi^{2}(6)=14.38, \mathrm{p}<0.05\right)$. However, weight category at age 7.5 was not found to predict relational bullying status (at age 8.5 ) for either boys $\left(\chi^{2}(6)=9.70\right.$, NS) or girls $\left(\chi^{2}(6)=3.29\right.$, NS). Compared to average weight boys, obese boys were 1.78 times more likely to be overt bullies, 1.40 times more likely to be overt victims, and 1.44 times more likely to be relational victims a year later, at age 8.5 (table 4). Underweight boys were also 0.69 times less likely to be overt victims than average weight boys (table 4).

Compared to average weight girls, obese girls were 1.52 times more likely to be overt victims, while underweight girls were 1.79 times more likely to be overt bullies (table 5).

The association of overt bullying and obesity persisted after adjustment for parental social class. Weight category at age

Table 2 Prevalence of underweight, average weight, overweight, and obese children at age 7.5

\begin{tabular}{lllll}
\hline & $\begin{array}{l}\text { Underweight } \\
\mathbf{n}(\%)\end{array}$ & $\begin{array}{l}\text { Average weight } \\
\mathbf{n}(\%)\end{array}$ & $\begin{array}{l}\text { Overweight } \\
\mathbf{n}(\%)\end{array}$ & $\begin{array}{l}\text { Obese } \\
\mathbf{n}(\%)\end{array}$ \\
\hline Girls & $468(12)$ & $2840(70)$ & $413(10)$ & $326(8)$ \\
Boys & $492(12)$ & $2945(71)$ & $351(8)$ & $375(9)$ \\
\hline
\end{tabular}


Table 3 Weight category (at age 7.5) by bullying status (at age 8.5)

\begin{tabular}{|c|c|c|c|c|c|c|c|c|}
\hline \multirow[b]{3}{*}{ Weight category } & \multicolumn{8}{|c|}{ Bullying status n (\%) } \\
\hline & \multicolumn{4}{|l|}{ Boys } & \multicolumn{4}{|l|}{ Girls } \\
\hline & Overt bully & Overt victim & Relational bully & Relational victim & Overt bully & Overt victim & Relational bully & Relational victim \\
\hline Underweight & $41(11)$ & $91(23)$ & $10(3)$ & $39(10)$ & $21(6)$ & $101(27)$ & $10(3)$ & $49(13)$ \\
\hline Average weight & $215(10)$ & $694(31)$ & $61(3)$ & 296 (13) & $74(3)$ & $581(26)$ & $45(2)$ & $354(16)$ \\
\hline Overweight & 35 (13) & $75(28)$ & 7 (3) & 28 (11) & $9(3)$ & $81(25)$ & $6(2)$ & 45 (14) \\
\hline Obese & 36 (14) & $91(36)$ & $6(2)$ & $45(18)$ & $11(4)$ & $86(34)$ & $5(2)$ & $42(17)$ \\
\hline
\end{tabular}

7.5 was found to predict overt bullying status (at age 8.5) for boys $\left(\chi^{2}(10)=20.86, \mathrm{p}<0.05\right)$, although not for girls $\left(\chi^{2}\right.$ $(10)=14.95$, NS). As with the unadjusted models, weight category at age 7.5 was not found to predict relational bullying status (at age 8.5) for either sex (boys: $\chi^{2}$ $(10)=12.38$, NS; girls: $\chi^{2}(10)=10.00$, NS). Compared to average weight boys, obese boys were 1.66 times more likely to be overt bullies and 1.54 times more likely to be overt victims a year later, at age 8.5 (table 4). Compared to average weight girls, obese girls were 1.53 times more likely to be overt victims (table 5 ).

\section{DISCUSSION}

This study reports a high prevalence of overweight and obesity, in line with previous reported prevalences in the UK. ${ }^{12}$ The prevalence of bullying victimisation was also similar to previously reported prevalences, ${ }^{16}{ }^{18}$ confirming that bullying is widespread among primary school children. More involvement in overt than relational bullying was reported for boys than girls, and no sex differences in relational bullying were found.

While limited evidence suggests that young children may show more aggression if they are obese, ${ }^{26}$ few, if any, studies have examined victimisation (overt and relational forms) by sex and weight categories in pre-adolescents. This study identifies the impact of obesity on peer victimisation, previously identified in adolescents. ${ }^{7-10}$ However, by examining this relationship for each sex separately, slight differences were established for boys and girls, as also reported in obese adolescents. ${ }^{8}{ }^{10}$

Previous research has shown a relationship between behaviour problems and an increased risk of becoming overweight. ${ }^{27}$ Inversely, these findings show that weight category can significantly predict future bullying involvement, with obese boys likely to be both victims and perpetrators of overt bullying, and obese girls more likely to be overt victims a year later. An overweight status of boys and girls was not found to significantly predict bullying involvement, suggesting that level of adiposity is significant.

Thus, the longitudinal nature of the data enabled us to establish that pathways for obesity and bullying, and adverse effects, also differ by gender in pre-adolescence. For boys, obesity can have different or mixed effects on peer relationships. Being obese pre-puberty may endow them with physical dominance through greater strength and resulting popularity in the peer group, and the ability to overtly dominate other children. ${ }^{19}$ On the other hand, other obese boys are likely to become victims of overt bullying. In girls there is no distinct advantage of being obese and physically stronger as most of their direct bullying is name calling; consequently, they are more likely to become victims of overt bullying. Nevertheless, bully-perpetrating is reported to increase in girls as they get older, and Janssen and colleagues $^{8}$ reported a relationship between bully-perpetrating and obesity in both boys and girls, in 15 to 16 year olds. Victimisation of obese pre-adolescents is likely because they deviate from appearance and physically slim ideals, which is found to be especially prevalent in pre-adolescent girls. ${ }^{28}$ Weight category and appearance therefore appears to have more disadvantages for girls than for boys, as has also been reported in adolescence. Adolescent obese girls are less likely to date and be involved in romantic relationships, and no differences are reported in the dating status of obese boys, ${ }^{10}$ suggesting that obesity in boys may be of less disadvantage if they are dominant in the peer group.

We also examined underweight pre-adolescents to see if having a slim physique impacted on victimisation, as reported in adolescents. ${ }^{9}$ While underweight boys were less likely to be victims of bullying at 8.5 years than average weight boys, underweight girls at age 7.5 were more likely to be overt bullies a year later than average weight girls. This further indicates that slimness predisposes to dominance and overt bullying in the peer group of girls, even at primary school age. The association for underweight and bullying however was not found to be significant after adjustment for parental social class, suggesting that the dominance of underweight girls is explained by being more likely of higher social class (non-manual)

Self-report in the bullying interview may underestimate the prevalence of bullying perpetrators. In fact, we had only a small frequency of "pure" bullies, while most who bullied others also reported being victims (that is, bully/victims). For reasons of statistical power, we decided to combine pure bullies and bully/victims as "bullies", as both are perpetrators. A higher rate of bully/victims compared to pure bullies is usually found in primary school than secondary school children. ${ }^{16}$ Further research that includes peer nominations of bullying may identify more bullies perceived by peers as "pure" bullies. However, within this study, the interview has been previously tested in large samples, ${ }^{16}{ }^{18}$ all interviewers were trained in probing during the interview, and the children were familiar with both the ALSPAC clinics and previous psychological assessment. For these reasons, we feel that socially desirable answers were expectantly reduced. Nevertheless, fewer children $(n=151)$ completed the relational bullying status questions in the interview, which followed those on overt bullying status; interviews were not completed if the interviewer sensed that the children were distressed, the children asked for the interview to stop, or if the interviewer ran out of time in the session. A further limitation is that we did not examine reasons for bullying involvement, and our findings relate solely to weight category. There may be other plausible reasons for subsequent bullying which we have explored elsewhere, ${ }^{29}$ and factors that may also be associated with both bullying and weight, such as self-esteem; this requires further investigation. Nevertheless, obesity is a good marker for health professionals and teachers for more likely involvement in subsequent bullying.

This study reiterates the growing evidence, and concern, of social and psychological consequences of childhood obesity over and above the long term health implications. Further 

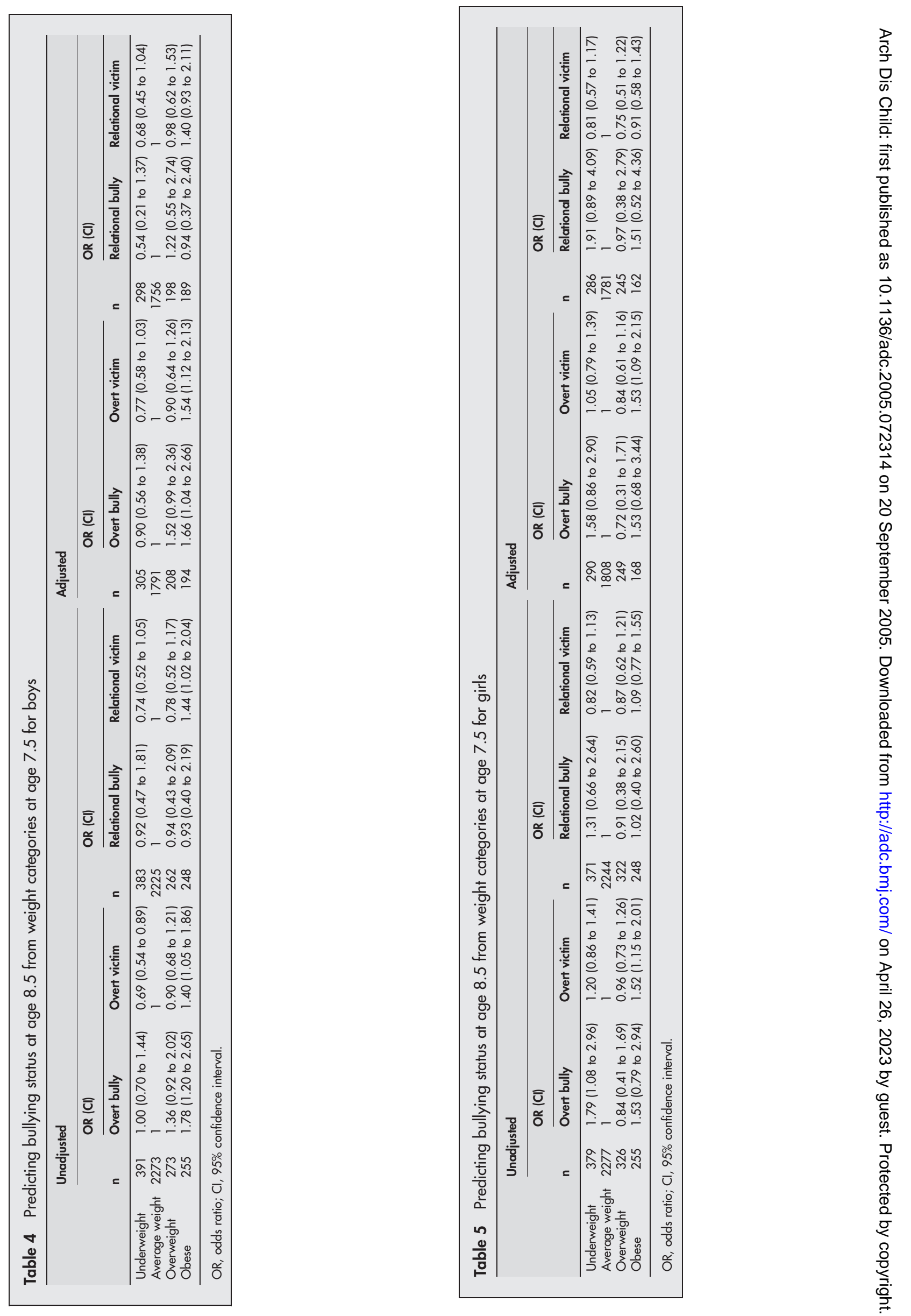


\section{What is already known on this topic}

- Children of all ages attribute negative qualities and prejudices towards obese peers

- Obese adolescents are victimised by peers

research should examine bullying behaviours and peer relationships in pre-adolescent obese children, to help explain the relationship between adiposity and social experiences, and how this relationship changes through childhood and adolescence. In-depth qualitative work, such as that conducted by Neumark-Sztainer and colleagues ${ }^{30}$ with obese adolescents, would, in particular, provide fruitful information about these experiences, informing those closest to these youth of their vulnerability to weight based teasing, coping strategies, and behavioural and psychological consequences. Our results suggest that coping strategies of these often marginalised young people may differ between sexes, with some obese boys using their physical strength to exercise dominance in their peer group. However, while $14 \%$ of the obese boys did present as overt bullies a year later, this finding should be interpreted with caution as existing evidence overwhelmingly suggests that obese boys are predominantly the subject of negative attention. This study suggests that parents, school personnel, and health professionals need to reduce the occurrence of this behaviour and the social marginalisation of obese children at an early age, ${ }^{31}$ before the strong importance on friendship networks for social and emotional development occurs during adolescence.

\section{ACKNOWLEDGEMENTS}

We are extremely grateful to all the mothers who took part and to the midwives for their cooperation and help in recruitment. The whole ALSPAC Study Team comprises interviewers, computer technicians, laboratory technicians, clerical workers, research scientists, volunteers, and managers who continue to make the study possible. This study could not have been undertaken without the financial support of the Medical Research Council, the Wellcome Trust, UK government departments, medical charities, and others. The ALSPAC study is part of the WHO initiated European Longitudinal Study of Pregnancy \& Childhood. We also thank Mark Davis (University of Bristol) for his comments on the manuscript.

\section{Authors' affiliations}

L J Griffiths, Centre for Paediatric Epidemiology and Biostatistics, Institute of Child Health, London, UK

D Wolke, J P Horwood, Department of Community Medicine, University of Bristol, Bristol, UK

A S Page, Department of Exercise and Health Sciences, University of Bristol, Bristol, UK

Competing interests: none declared

\section{REFERENCES}

1 Bundred PD, Kitchiner D, Buchan I. Prevalence of overweight and obese children between 1989 and 1998: population based series of cross sectional studies. BMJ 2001;322:1-4.

2 Reilly JJ, Dorosty AR. Epidemic of obesity in UK children. Lancet 1999;354:1874-5.

3 Falkner NH, Neumark-Sztainer D, Story M, et al. Social, educational, and psychological correlates of weight status in adolescents. Obes Res $2001 ; 9: 32-42$

4 Gortmaker SL, Must A, Perrin JM, et al. Social and economic consequence of overweight in adolescence and young adulthood. N Engl J Med 1993:329:1008-12.

\section{What this study adds}

- Pre-adolescent obesity can have damaging social consequences. Pre-adolescent obese children are more often involved in bullying than their average weight peers

- Pathways and adverse effects differ by sex. While obese girls and boys are victims, obese boys can also be perpetrators of bullying

5 Must A Strauss RS. Risks and consequences of childhood and adolescent obesity. Int J Obes Relat Metab Disord 1999;23:S2-11.

6 Wardle J, Volz C, Golding C. Social variation in attitudes to obesity in children. Int J Obes Relat Metab Disord 1995;9:562-9.

7 Eisenberg ME, Neumark-Sztainer D, Story M. Associations of weight-based teasing and emotional well-being among adolescents. Arch Pediatr Adolesc Med 2003; 157:733-8.

8 Janssen I, Craig WM, Boyce WF, et al. Associations between overweight and obesity with bullying behaviors in school-aged children. Pediatrics 2004:113:1187-94.

9 Neumark-Sztainer D, Falkner N, Story M, et al. Weight-teasing among adolescents: correlations with weight status and disordered eating behaviors. Int J Obes Relat Metab Disord 2002;26:123-31.

10 Pearce MJ, Boergers J, Prinstein MJ. Adolescent obesity, overt and relational peer victimization, and romantic relationships. Obes Res 2002;10:386-93.

11 Olweus D. Sweden. In: Smith PK, Morita Y, Junger-Tas J, Olweus D, Catalano $R$, Slee $P$, eds. The nature of school bullying: a cross-national perspective. London: Routledge, 1999:10.

12 Whitney I, Smith PK. A survey of the nature and extent of bullying in junior/ middle and secondary schools. Educational Research 1993;35:3-25.

13 Bjokquist K. Sex differences in physical, verbal and indirect aggression: a review of recent research. Sex Roles 1994;30:177-88.

14 Crick NR, Grotpeter JK. Relational aggression, gender, and socialpsychological adjustment. Child Dev 1995;66:710-22.

15 Smith PK, Ananiadou K. The nature of school bullying and the effectiveness of school-based interventions. Journal of Applied Psychoanalytic Studies 2003;5:189-209.

16 Wolke D, Woods S, Stanford K, et al. Bullying and victimization of primary school children in England and Germany: prevalence and school factors. Br J Psychol 2001;92:673-96.

17 Hawker DSJ, Boulton MJ. Twenty years' research on peer victimization and psychosocial maladjustment: a meta-analytic review of cross-sectional studies. $J$ Child Psychol Psychiatry 2000;41:441-55.

18 Wolke D, Woods S, Bloomfield L, et al. The association between direct and relational bullying and behaviour problems among primary school children. J Child Psychol Psychiatry 2000;41:989-1002.

19 Olweus D. Annotation: bullying at school: basic facts and effects of a school based intervention program. J Child Psychol Psychiatry 1994;35:1171-90.

20 Wolke D, Stanford K. Bullying in school children. In: Messer D, Millar S, eds. Developmental psychology. London: Arnold, 1999

21 Langnäse K, Mast M, Müller MJ. Social class differences in overweight of prepubertal children in northwest Germany. Int J Obes Relat Metab Disord 2002;26:566-72.

22 Golding J, Pembrey M, Jones R. ALSPAC-the Avon Longitudinal Study of Parents and Children. I. Study methodology. Paediatr Perinat Epidemiol 2001;15:74-87.

23 Cole TJ, Freeman JV, Preece MA. Body mass index reference curves for the UK, 1990. Arch Dis Child 1995;73:25-9.

24 Child Growth Foundation. UK cross-sectional reference data: 1990. London: Child Growth Foundation, 1996.

25 Office of Population Censuses \& Surveys. Standard occupational classification. London: Her Majesty's Stationery Office, 1991.

26 Young-Hyman D, Schlundt DG, Herman-Wenderoth L, et al. Obesity, appearance, and psychosocial adaptation in young African American appearance, and psychosocial adaptation in you
children. J Pediatr Psychol 2003;28:463-72.

27 Lumeng JC, Gannon K, Cabral HJ, et al. Association between clinically meaningful behaviour problems and overweight in children. Pediatrics 2003; 112:1138-45.

28 Hill AJ, Pallin V. Dieting awareness and low self-worth: related issues in 8-year old girls. Int J Eat Disord 1998;24:405-13.

29 Horwood J, Waylen A, Herrick D, et al. Common visual defects and peer victimization in children. Invest Ophthalmol Vis Sci 2005;46:1177-81.

30 Neumark-Sztainer D, Story M, Loren F. Perceived stigmatization among overweight African- American and Caucasian adolescent girls. J Adol Health 1998;23:264-70

31 Arora CMJ. Is there any point in trying to reduce bullying in secondary schools? Educational Psychology in Practice 1994;10:155-62. 